\title{
Mobility during and after training: autobiography and advice to early career colleagues
}

\author{
Carolina Torres ${ }^{1}$, Anna Elisabeth Frick ${ }^{2,3}$ \\ ${ }^{1}$ Department of Thoracic Surgery, Pulido Valente Hospital, Lisbon, Portugal; ${ }^{2}$ Department of Thoracic Surgery, University Hospitals Leuven, \\ Leuven, Belgium; ${ }^{3}$ Department of Cardiovascular Sciences, Unit of Anaesthesiology and Algology, Catholic University of Leuven, Leuven, Belgium \\ Contributions: (I) Conception and design: All authors; (II) Administrative support: None; (III) Provision of study materials or patients: None; (IV) \\ Collection and assembly of data: All authors; (V) Data analysis and interpretation: None; (VI) Manuscript writing: All authors; (VII) Final approval of \\ manuscript: All authors. \\ Correspondence to: Anna Elisabeth Frick. Department of Cardiovascular Sciences, University Hospital Leuven, Herestraat 49, 3000 Leuven, Belgium. \\ Email: annaelisabeth.frick@uzleuven.be.
}

\begin{abstract}
Mobility programs can be a valuable enhancement to medical formation and career, either during or after training as part of an internship or as a fellowship. In the case of surgery, the opportunity to visit departments who offer a broader range of operations than the home institution, learn new clinical and surgical techniques are unique possibilities to expand surgical and clinical daily routine practice but also to meet colleagues and exchange experiences for future collaboration and networking.
\end{abstract}

Keywords: Medical career; mobility; training

Submitted Nov 12, 2018. Accepted for publication Jan 16, 2019.

doi: $10.21037 /$ jtd.2019.01.71

View this article at: http://dx.doi.org/10.21037/jtd.2019.01.71

\section{Introduction}

Both authors undertook international mobility programs during their thoracic surgery training. In this article, they describe their personal experience, reflect on its importance in medical formation and attempt to provide guidance to those considering joining such programs.

\section{Historical background and actuality}

Mobility during surgical training was not established in the $21^{\text {st }}$ century in a society with a well-developed and uncomplicated access to a social network connected with surgeons all over the world. In fact, the first early American pioneers who documented their fellowships in Europe were William Stewart Halsted and Edward D. Churchill. From 1878 to 1880 Halsted visited Europe (Austria and Germany) and in 1892 he became Professor at the John Hopkins University in Baltimore. He learnt different surgical and clinical aspects and implemented them in his own further thoracic surgery career pathway in the US (1-3). The last decades American, Asian and European surgery societies have established scholarships and fellowships to support careers of surgeons (2).

At the present time, surveys have shown a progressive quest for mobility programs, with $60-85 \%$ of Canadian residency graduates from several specialties intending to pursue a fellowship, with similar findings from studies in the UK and the US (4). The willingness to undergo an international mobility program has also been well investigated in a north-American survey: out of 742 residents, $682(92 \%)$ were interested to participate in an international rotation during their training (5).

\section{Autobiography}

AE Frick started, after the Austrian common trunk, her training in thoracic surgery in Vienna at the Otto-Wagner Hospital, followed by 3 years at the Chest Hospital Berlin, Germany. Her training at the Chest Hospital Berlin provided formation in open surgery and video-assisted thoracoscopic surgery (VATS) for various thoracic diseases 
including the pleura, mediastinum, diaphragm and the lung. In 2017 she started a 1-year surgical fellowship at the Department of Thoracic Surgery in Leuven (UZ Leuven), Belgium, and accomplished the Austrian national board exam for thoracic surgery. The aim of this fellowship was to learn more about benign and malignant esophageal diseases, lung transplantation, congenital diaphragmatic and lung diseases, and benign and malignant diseases of the pleura, mediastinum, trachea and lung. The department of Thoracic Surgery in Leuven provides a significant high volume of esophageal cases. She had the opportunity to learn more about surgical approaches like left thoracophreno-laparotomy, hybrid Ivor Lewis surgery (right thoracotomy and laparoscopy) and minimal invasive esophagectomy (MIE) with cervical anastomoses. With implementing the enhanced recovery after surgery (ERAS) protocols in patients with esophageal surgery she improved her knowledge in efficient postoperative management. But also, in the field of lung transplantation in clinic and basic research, Leuven provides a long-standing experience which was of particular interest of the author. The author had also the chance to join grand rounds, multidisciplinary tumour boards for esophageal and lung diseases, and national and international symposiums organized by the host institution.

Overall, the 1 year fellowship in Leuven offered a broad exposure to different thoracic surgeries, improved surgical skills and deepened the knowledge in thoracic diseases, research and the daily hospital routine within a very dedicated and professional thoracic surgery team.

C Torres is a Lisbon based thoracic surgeon, having recently completed a 5 -year training program to become a specialist. She accomplished her thoracic surgery training in a general thoracic surgery department, especially dedicated to the surgical treatment of thoracic malignancies (Pulido Valente Hospital). During her final year of training, she underwent a 6-month clinical rotation in the Department of Thoracic Surgery of Strasbourg (Hôpitaux Universitaires de Strasbourg, France). The decision of moving to another department at a final stage of her residency was based from the premise of supplementing her curriculum with a formation in lung transplant, a specific valence which her department could not provide, besides a solid exposure to most thoracic surgical pathologies. For its vast surgical activity, strong academic profile and recognized role in medical training, Strasbourg was the ideal choice. The routine in Strasbourg consisted in daily participation in the operating theatre along with patient care during ward rounds as well as those staying in intensive care units, responding to urgent/emergent calls and taking part in the lung transplantation activity. This was an extensive, all-embracing participation, including discussion of potential lung donors, travelling to donor site and lung retrieval, to implantation, implementation of cardiopulmonary bypass when indicated and post-operative management. The author also had the opportunity to widen her surgical lexicon to tracheal resections, robot assisted thoracic surgery radical thymectomies, different approaches in lung anatomical resections and new techniques in complex chest wall reconstruction surgery. However, the professional growth in Strasbourg wasn't limited to the operating theatre. It was rather a continuous learning process, benefiting from integration into a highly motivated team, in a department with a substantial turnover of patients and demand for thoracic consultation. In addition, the fact that the department had permanently new visitors-trainees and fellows from different parts of the world—created a special environment for debate and sharing ideas.

In conclusion, this surgical rotation at the end of the 5-year training period was a milestone in the author's professional growth, allowing strengthening of the previous formation, achievement of new skills and deep reflection on daily practices.

\section{Advice to early career colleagues}

\section{The reasons to go}

The authors share a "go!" point of view in what concerns embracing a mobility program. Despite the difficulties involved in overcoming the language and culture barriers and adapting to a different working environment, the learning experience in a new department is gratifying.

The possibility to get an insight to a different practice, to acquire determined skills and the encompassed maturation process are some of the aspects already (6). Advantages for a research fellowship have also been demonstrated in retrospective studies, with research fellows reporting better academic achievement and greater career satisfaction than their peers (7). Recently, the task force group of HERMES (Harmonized Education in Respiratory Medicine for European Specialists) by the ERS (European Respiratory Society) in cooperation with the ESTS (European Society of Thoracic Surgery) published a syllabus and curriculum about the content of required knowledge for thoracic surgery training $(8,9)$. It includes a broad spectrum of topics, including lung transplantation, as well as paediatrics thoracic pathology, esophageal and tracheal surgery, which are not 
practiced in all thoracic departments. This means that a mobility program can represent a way to acquire the skills and qualification in certain areas that the home department may not offer. Besides, more and more thoracic surgeons apply for a diploma by The European Board of Thoracic Surgery (EBTS) to achieve a certificate of a European Board to be recognized for independent practice (10), therefore, it becomes increasingly more relevant to have a fuller curriculum and practice independently in Europe. Considering that thoracic surgery training varies in length and contents within Europe (8) the possibility to undergo a mobility program can be a crucial step to supplement the curriculum and to get ready to apply to the EBTS certificate.

Additionally, working in a new department is the opportunity to meet colleagues and exchange experiences for international collaborations.

\section{Possible obstacles}

Caution must be taken when choosing the right time to undergo an internship/fellowship-one must ensure to have the pre-requirements to work in a determined department including the foreign language knowledge and special surgical skills if required from the host institution (for example, in a lung transplant rotation it is important to understand the basic concepts of cardiopulmonary bypass and the correct technique of cannulation).

Funding for scholarships and fellowships remain difficult though many societies provide a financial support for surgical clinical training and formal research training.

\section{Establish a plan, have a mentor}

The new working reality can be overwhelming, and one can easily be thrown in the routine of the department. It is imperative to clearly define the learning objectives, and to draw a goal-oriented plan that can be achieved during that period. Having a local mentor can be helpful to guide the activities and accomplish the expectations but also for feedback during the progress.

To capture a learning process, it can be helpful to create a record as written reports of surgical interventions, pictures or videos. These records will help to integrate the new information when returning to the home department.

\section{Share}

While accomplishing the learning objectives during the mobility period, sharing with the home team the recently acquired knowledge and know-how will be a powerful method to prolong and to endure the experience, to empower the team as whole and contribute to a harmonization of practice. It also facilitates discussion and further reflection in daily practices and possible help to offer a higher level of standard of care.

\section{Conclusions}

An international mobility program, during or after surgical training, is a fruitful opportunity with high educational benefits. It enables increased confidence and security, which is especially important to jobs of greater responsibility.

The authors believe that the establishment of international internships and fellowships should be encouraged by the national and international surgery societies.

\section{Acknowledgments}

Funding: None.

\section{Footnote}

Provenance and Peer Review: This article was commissioned by the Guest Editor (Gilbert Massard) for the series "Training in Pulmonary Medicine and Surgery" published in fournal of Thoracic Disease. The article has undergone external peer review.

Conflicts of Interest: Both authors have completed the ICMJE uniform disclosure form (available at http://dx.doi. org/10.21037/jtd.2019.01.71). The series "Training in Pulmonary Medicine and Surgery" was commissioned by the editorial office without any funding or sponsorship. The authors have no other conflicts of interest to declare.

Ethical Statement: The authors are accountable for all aspects of the work in ensuring that questions related to the accuracy or integrity of any part of the work are appropriately investigated and resolved.

Open Access Statement: This is an Open Access article distributed in accordance with the Creative Commons Attribution-NonCommercial-NoDerivs 4.0 International License (CC BY-NC-ND 4.0), which permits the noncommercial replication and distribution of the article with the strict proviso that no changes or edits are made and the 
original work is properly cited (including links to both the formal publication through the relevant DOI and the license). See: https://creativecommons.org/licenses/by-nc-nd/4.0/.

\section{References}

1. Borst HG. The Wanderjahr of Edward D. Churchill. Excerps from the book by J. G. Scannell, Boston. Langenbecks Arch Chir 1992;377:195-203.

2. Fong Y, Early K, Deane SA, et al. American College of Surgeons International scholarship programs: 40-year history of support for International Surgical Education. J Am Coll Surg 2010;211:279-84.e1-8.

3. Sudarshan M, Cassivi SD. Visiting scholarships in cardiothoracic surgery: a valuable experience for fostering collaboration. J Thorac Dis 2017;9:E1122-4.

4. Karpinski J, Ajjawi R, Moreau K. Fellowship training: a qualitative study of scope and purpose across one department of medicine. BMC Med Educ 2017;17:223.

5. Powell AC, Casey K, Liewehr DJ, et al. Results of a

Cite this article as: Torres $\mathrm{C}$, Frick AE. Mobility during and after training: autobiography and advice to early career colleagues. J Thorac Dis 2021;13(3):2075-2078. doi: 10.21037/ jtd.2019.01.71 national survey of surgical resident interest in international experience, electives, and volunteerism. J Am Coll Surg 2009;208:304-12.

6. Ilonen IK, McElnay PJ. Research and education in thoracic surgery: the European trainees' perspective. J Thorac Dis 2015;7:S118-21.

7. Anderson KD, Mavis BE. The relationship between career satisfaction and fellowship training in academic surgeons. Am J Surg 1995;169:329-33.

8. Massard G, Tabin N, Mitchell S, et al. A harmonised European training syllabus for thoracic surgery: report from the ESTS/ERS task force group. Eur Respir J 2018;51:1800370.

9. Massard G, Tabin N, Mitchell S, et al. A harmonized European training syllabus for thoracic surgery: report from the ESTS-ERS task force. Eur J Cardiothorac Surg 2018;54:214-20.

10. Frick AE, Massard G. Thoracic surgery training in Europe-the perspective of a trainee. J Thorac Dis 2017;9:S218-22. 